\title{
Homocysteine, not high-sensitivity C-reactive protein, associates with the intima-media thickness of carotid artery and arterial stiffness
}

\author{
Dongmei Miao ${ }^{1}$, Tongrui Huang ${ }^{2}$, Ping $\mathrm{Ye}^{1 \star}$, Wenkai $\mathrm{Xiao}^{1}$, Jinyao Zhang ${ }^{1}$ and Hongmei $\mathrm{Wu}^{1}$ \\ ${ }^{1}$ Department Two of Geriatric Cardiology, Chinese PLA General Hospital, Beijing, 100853, China. \\ ${ }^{2}$ Department of Cadres, Bethune International Peace Hospital, Shijiazhuang, 50082, China.
}

Accepted 30 January, 2013

\begin{abstract}
The study objective was to assess the relationship between carotid intima-media thickness (IMT) and arterial stiffness in subjects with hypertension, and to investigate the risk factors for increasing carotid IMT and arterial stiffening. 336 eligible residents participated in a community-based survey. Arterial stiffness and carotid intima-media thickness (IMT) were evaluated using carotid arterial stiffness parameter and high-resolution B-mode ultrasonography in 232 subjects with hypertension and 104 control subjects. Serum homocysteine and hs-C reactive protein (CRP) were measured. Arterial stiffness parameter and carotid IMT were significantly higher in the subjects with hypertension than those in the control $(P<0.05)$. There was a significant positive correlation between the carotid IMT and arterial stiffness parameter in both the subjects with hypertension $(r=0.421, P<0.001)$ and from the control group ( $r=0.337, P<0.001)$. Homocysteine and high-sensitivity C-reactive protein (hs-CRP) increased with arterial stiffness and IMT $(P<0.05)$. Homocysteine, but not hs-CRP, was independently related to arterial stiffness parameter $(P<0.01)$ when age, smoking, hypertension, estimated glomerular filtration rate (eGFR) and the roles of high density lipoprotein (HDL)- cholesterol were accounted for $(R 2=0.330, P<0.001)$. On the other hand, not only homocysteine but hs-CRP were independently related to IMT ( $P<0.01$, respectively) when age, smoking, hypertension and the roles of low density lipoprotein (LDL)-cholesterol were accounted for $(R 2=0.361, P<0.001)$. The results indicate that there was association between arterial atherotic (structural) and sclerotic (functional) changes. Homocysteine, but not hs-CRP, associates with the changes of carotid artery IMT and arterial stiffness.
\end{abstract}

Key words: Arterial stiffness, intima-media thickness, homocysteine, hs-CRP.

\section{INTRODUCTION}

Subjects with hypertension and ageing have accelerated atherosclerotic vascular changes (Eren et al., 2004). Arterial wall thickening and stiffening often appear at the same time, which may partly delineate different atherosclerotic processes (Eren et al., 2004; Ikonomidis et al.,

*Corresponding author. E-mail: cnpingye@126.com. Tel: +8610-66876329. Fax: +86-10-66876349. et al., 2008). Atherosclerosis involves a combination of fatty degeneration (atherosis) and of vessel stiffening (sclerosis) of the arterial wall (Sharrett et al., 2006). There-fore, atherosclerosis should be evaluated based on two aspects: Atherosis, which reflects structural changes in the intima and media of vascular walls and provides information about vessel wall anatomy; and sclerosis, which reflects changes in vascular distensibility and relates to vessel function (Jourdan et al., 2005).

In animal studies, a direct relationship has been 
established between regression of atherosis and an increase in arterial distensibility (Farrar et al., 1980). Some clinical trials also demonstrated that carotid arterial stiffness was associated with the morphological changes (Niki et al., 2002; Taniwaki et al., 1999). The association of arterial stiffness and structural changes in the intima and media of vascular walls in different age periods are required to be studied in detail and with priority remains to be elucidated. Furthermore, the study tried to explore the predictors for this process from metabolic factors and chronic subclinical inflammation.

Chronic subclinical inflammation, commonly assessed using high-sensitivity C-reactive protein (hs-CRP), has been associated with obesity and coronary heart disease (Bahrami et al., 2008; Niki et al., 2002; Taniwaki et al., 1999). As we know, inflammation is important in the pathogenesis and progression of endothelial dysfunction and fatty degeneration (atherosis) (Chrysohoou et al., 2009), and hs-CRP has been established as an independent prognostic predictor for IMT (Braunwald, 2008). Controversy surrounds, at present, regarding the association between hs-CRP and arterial stiffness indices (Tomiyama et al., 2004). Homocysteine, as a marker for metabolism, has recently been shown to be independent of cardiovascular events (Robinson, 2002). Increased plasma homocysteine levels have been considered as an independent risk factor for cardiovascular disease (Welch and Loscalzo, 1998; Vasan et al., 2003; Vollset et al., 2001). However, the influence of homocysteine in the development of IMT and arterial stiffness has not been clarified at present (de Bree et al., 2006; Anan et al., 2007).

The aims of the present study were to assess the relationship between carotid IMT and arterial stiffness, and to explore a possible approach to determine the association between regression of atherosis and an increase in arterial distensibility by the way of identifying markers for metabolic disorders and chronic subclinical inflammation.

\section{MATERIALS AND METHODS}

This study was conducted in accordance with the declaration of Helsinki and with approval from the Ethics Committee of Chinese PLA General Hospital. Written informed consent was obtained from all participants. Participants with hypertension $(n=232)$ were enrolled into the study consecutively. The community has a population of 2334 residents, and 1867 residents participated in the health survey. Of these participants, 452 subjects were defined as hypertension according to the following criteria, and 232 subjects had not taken medicines for hypertension in recent three weeks. Hypertension was defined as a resting systolic blood pressure $\geq$ 140 or a resting diastolic blood pressure $\geq 90$, and the systolic pressure and the diastolic pressure were the means of measurements on three occasions. We had excluded subjects with evidence of cardiovascular complications as indicated by medical history or physical examination, with history of diabetes or fasting plasma glucose $>7.0 \mathrm{mmol} / \mathrm{l}$, with taking statins and with any condition preventing echocardiography evaluation. Age and gendermatched normotensive control subjects $(n=104)$ were recruited randomly from the same community during the same period. All participants were grouped by age according to their corresponding arterial stiffness (Niki et al., 2002): the group of $<45$ years, 45 to 55 years, 56 to 65 years and $>65$ years.

All the participants completed a self-administered questionnaire about smoking habits and diet. Exposure to smoking was estimated as the product of the number of years of smoking and the number of tobacco products smoked daily at the time of the study. That product was expressed in statistical analysis as cigarette-years. The intakes of folate, vitB6 and vitB12 daily were gotten from three days averaged through diet questionnaire survey and food- $B$ vitamins conversion system. We used a brief food frequency questionnaire (FFQ) designed specifically for estimating intakes of folate, vitamins $B(6)$ and $B(12)$, and covering 21 food items (Yoshino et al., 2010). Blood pressure was determined with a standard mercury sphygmomanometer and cuffs adapted to the arm circumference after the subject had rested for at least $15 \mathrm{~min}$ by professional doctors. The systolic blood pressure was taken as the point of appearance of Korotkoff sounds, and the diastolic blood pressure as the point of disappearance of the sounds. Results are reported as averages of three measurements (Table 1).

\section{Measurement of arterial stiffness parameter}

Arterial wall stiffness was expressed by the arterial stiffness parameter $\beta$, which was measured through e-tracking technology of ultrasound on the right carotid artery by the machine ( $\alpha-10$, Aloka, Tokyo, Japan) equipped with a $7.5-\mathrm{MHz}$ linear array probe and calculated according to the formula: In [(Ps-Pd)]/[(Ds- Dd)/Dd], where Ps and Pd were the mean values of three times of simultaneously measured brachial systolic blood pressure and diastolic blood pressure, respectively. Ps and Pd were, measured using an automated sphygmomanometer (705CP, Omron, Dalian, China), and Ds and Dd are the maximal and minimal diameters of the common carotid artery, respectively measured using ultrasonic highresolution wall tracking. Measurements were taken as a mean of five beats (Figure 4).

\section{Ultrasonographic measurements of carotid IMT}

B-mode imaging of the carotid artery was performed with a high resolution real-time ultrasonograph ( $\alpha-10$, Aloka, Tokyo, Japan). All the participants were examined in the supine position. The examination included the bilateral common carotid artery and the carotid bulb. These regions were scanned in the longitudinal and the transverse projections. In each longitudinal projection, the IMT was measured at the site with the greatest thickness. IMT was defined as the distance between the places with the strongest ultrasound reflection, from the leading edge of the lumen-intima interface to the leading edge of the media-adventitia interface. Three still images from the same section of the artery were used for the measurement, and the mean value was calculated.

\section{Biochemistry parameters measurements}

Venipuncture was performed in the morning on patients and healthy control subjects after overnight fasting and maintained at $4^{\circ} \mathrm{C}$ for $\leq 2$ $\mathrm{h}$ before being centrifuged at $1200 \mathrm{~g}$ for $15 \mathrm{~min}$. Serum aliquots were frozen at $-80^{\circ} \mathrm{C}$ until assays were performed. Concentrations of fasting glucose, total cholesterol, triglyceride, HDL-c and LDL-c were determined using the Roche enzymatic assays (Roche 
Table 1. Clinical characteristics of hypertensive and control subjects.

\begin{tabular}{lcc}
\hline Characteristic & Hypertensive subject $(\mathbf{n}=\mathbf{2 3 2})$ & Control subject $(\mathbf{n}=\mathbf{1 0 4})$ \\
\hline Age $($ years $)$ & $56.7 \pm 13.7$ & $57.5 \pm 14.4$ \\
Sex $(\mathrm{M} / \mathrm{F})$ & $128 / 94$ & $54 / 50$ \\
Body mass index $\left(\mathrm{kg} / \mathrm{m}^{2}\right)$ & $24.8 \pm 3.3^{\#}$ & $22.9 \pm 2.8$ \\
Cigarette-years & $474 \pm 411^{\#}$ & $248 \pm 178$ \\
Systolic blood pressure $(\mathrm{mmHg})$ & $145 \pm 16^{\#}$ & $126 \pm 15$ \\
Diastolic blood pressure $(\mathrm{mmHg})$ & $80 \pm 8^{\#}$ & $73 \pm 10$ \\
Total cholesterol $(\mathrm{mmol} / \mathrm{L})$ & $5.23 \pm 1.08^{*}$ & $4.86 \pm 0.75$ \\
HDL-cholesterol $(\mathrm{mmol} / \mathrm{L})$ & $1.21 \pm 0.38^{\#}$ & $1.39 \pm 0.27$ \\
LDL-cholesterol $(\mathrm{mmol} / \mathrm{L})$ & $3.50 \pm 1.11^{*}$ & $3.09 \pm 1.05$ \\
Triglycerides $(\mathrm{mmol} / \mathrm{L})$ & $1.48 \pm 0.89$ & $1.34 \pm 0.78$ \\
Fasting plasma glucose $(\mathrm{mmol} / \mathrm{L})$ & $5.36 \pm 0.80^{*}$ & $5.10 \pm 0.76$ \\
Creatinine $(\mathrm{mmol} / \mathrm{L})$ & $80.9(66.2-81.0)^{*}$ & $65.7(51.8-72.2)$ \\
eGFR $\left(\mathrm{ml} / \mathrm{min} / 1.73 \mathrm{~m}{ }^{2}\right)$ & $82.8 \pm 16.5^{\#}$ & $91.2 \pm 15.2$ \\
Homocysteine $((\mu \mathrm{mol} / \mathrm{L}))$ & $17.6(13.8-27.9)$ & $8.22(6.01-12.6)$ \\
hs-CRP $(\mathrm{mg} / \mathrm{dL})$ & $0.24(0.11-0.37)$ & $0.14(0.08-0.25)$ \\
Carotid IMT $(\mathrm{mm})$ & $0.88 \pm 0.38^{\#}$ & $0.62 \pm 0.16$ \\
Arterial stiffness parameter & $9.05 \pm 2.19^{\#}$ & $7.65 \pm 1.18$ \\
Folate $(\mu \mathrm{m} / \mathrm{d})$ & $217.3 \pm 97.7^{\#}$ & $308 \pm 113.2$ \\
Vitamin $\mathrm{B}_{6}(\mathrm{mg} / \mathrm{d})$ & $0.50 \pm 0.14^{\#}$ & $0.83 \pm 0.26$ \\
Vitamin $\mathrm{B}_{12}(\mu \mathrm{d} / \mathrm{d})$ & $0.69 \pm 0.18^{\#}$ & $1.00 \pm 0.22$ \\
\hline
\end{tabular}

Exposure to smoking was estimated as the product of the number of years of smoking and the number of tobacco products smoked daily at the time of the study. That product was expressed in statistical analysis as cigarette-years. HDL-c, high-density lipoprotein cholesterol; LDL-c, low-density lipoprotein cholesterol; eGFR, estimated glomerular filtration rate; hs-CRP, high-sensitivity $\mathrm{C}$-reactive protein. ${ }^{\star} P<0.05, \# P<0.001$ vs. control subjects.

Diagnostics $\mathrm{GmbH}$, Mannheim, Germany) on a Roche autoanalyser (Roche Diagnostics, Indianapolis, Indiana). Homocysteine was determined by enzymatic assay (Roche Diagnostics $\mathrm{GmbH}$, Germany). hs-CRP was measured using immunoturbidometry (Siemens Healthcare Diagnostics Inc.) with the help of -Siemenes RXL-MAX, (Germany). The inter-assay variations for the biomarkers were as follows: hs-CRP, $4.6 \%$ and homocysteine, $4.1 \%$. Concentrations of serum creatinine were measured by enzymatic assay (Roche Diagnostics $\mathrm{GmbH}$ ) on a Hitachi 7600 autoanalyser (Hitachi, Tokyo, Japan). The plasma creatinine was standardized using a calibration equation: Jaffe's kinetic method $\mathrm{Scr}$ $(\mathrm{mg} / \mathrm{dL})=0.795 \times[$ enzymatic method Scr $(\mathrm{mg} / \mathrm{dL})]+0.29$. The estimated glomerular filtration rate (eGFR) was calculated with the Chinese modified Modification of Diet in Renal Disease (C-MDRD) equation:

eGFR $(\mathrm{mL} / \mathrm{min} / 1.73 \mathrm{~m} 2)=175 \times$ standardized creatinine $(\mathrm{mg} / \mathrm{dL})$ -1.234 ×age (year) $-0.179 \times 0.79$ (if female).

All testing was performed by well-trained personnel blinded to clinical data in the Department of Biochemistry of Chinese PLA General Hospital.

\section{Statistical analysis}

Characteristics are reported as percentages for categorical variables and mean \pm standard deviation (SD) or median (with interquartile range) for continuous variables. Student's $t$ test or Chisquare test was used to compare differences between groups. The relationship between IMT values and arterial stiffness in the control and hypertensive subjects were examined by linear regression analysis. The relationship of homocysteine and hs-CRP with IMT values and arterial stiffness were examined by spearman analysis. The relationship of homocysteine with $B$ vitamins and smoking (present as cigarette-years) were also analyzed by spearman analysis. Multiple regression analyses were performed to identify the predictors of homocysteine, carotid IMT and arterial stiffness. All statistical procedures were performed using SPSS statistical package, version 13.0 (SPSS Inc., Chicago, Illinois). Intercorrelated independent variables were removed from the regression model if multicollinearity was detected by a tolerance $<0.10$ or a variance inflation factor $>10$. $P<0.05$ was considered significant.

\section{RESULTS}

\section{Clinical characteristics}

The clinical characteristics of subjects are shown in Table 1. The subjects aged from 40 to 72 year. There were no differences in age or the male-female ratio between the control and hypertensive subjects. BMI, cigarette-years, blood pressure, the levels of plasma lipids excepting for HDL-C, blood glucose and renal function were significantly higher in the hypertensive subjects than in the control subjects. All of the participants had not taken B vitamins supplements, containing folate, VitB6 and other $B$ vitamins in the six months. Homocysteine and hs-CRP were significantly higher in the hypertensive subjects than in the control subjects. The level of HDL cholesterol and 


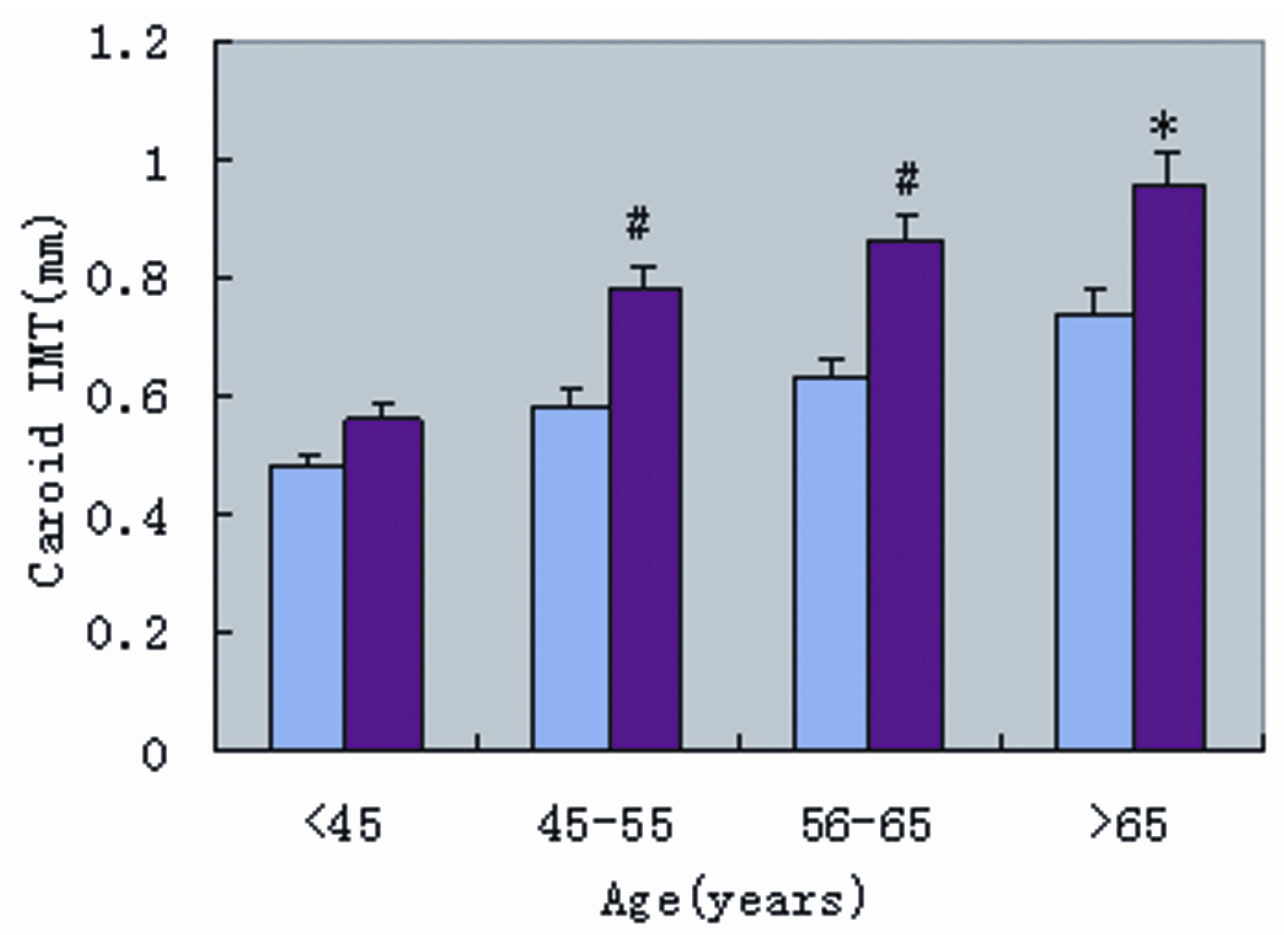

Figure 1. Bar graphs showing mean values of IMT of carotid artery in control subjects $(n=104$ blue bar) and patients with hypertension ( $n=232$ purple bar) by age group. ${ }^{*} P<0.05, \# P<0.001$ vs. control subjects.

and the intakes of $B$ vitamins were lower in the hypertensive subjects than in the control subjects.

\section{Carotid IMT in different age durations}

The IMT values of the carotid artery in the groups of 45to 55 -year-old $(0.78 \pm 0.32 \mathrm{~mm}, \mathrm{n}=88), 56$ - to 65 -year-old $(0.86 \pm 0.28 \mathrm{~mm}, \mathrm{n}=72)$, and $>65$ years $(0.96 \pm 0.30$ $\mathrm{mm}, \mathrm{n}=46$ ) were significantly higher than those in the age-matched control subjects $(0.58 \pm 0.12 \mathrm{~mm}, \mathrm{n}=34$; $0.63 \pm 0.17 \mathrm{~mm}, \mathrm{n}=36 ; 0.74 \pm 0.20 \mathrm{~mm}, \mathrm{n}=18$, respectively) with the exception of the group of less than 45 years $(0.56 \pm 0.14 \mathrm{~mm}, \mathrm{n}=26$ vs. $0.48 \pm 0.11 \mathrm{~mm}, \mathrm{n}=16)$ (Figure1). The carotid IMT was significantly higher in the hypertensive subjects $(0.88 \pm 0.38 \mathrm{~mm}, \mathrm{n}=232)$ than in the control subjects $(0.62 \pm 0.16 \mathrm{~mm}, \mathrm{n}=104)(\mathrm{P}<$ $0.001)$. There is no gender difference in the presence of carotid IMT.

\section{Arterial stiffness in different age durations}

The arterial stiffness values of the hypertensive subjects in the group of $<45$ years $(6.94 \pm 0.63 \mathrm{~m} / \mathrm{s}, \mathrm{n}=26)$, $45-$ 55 years $(8.78 \pm 1.33 \mathrm{~m} / \mathrm{s}, \mathrm{n}=88), 56-65$ years $(9.37 \pm$ $1.81 \mathrm{~m} / \mathrm{s}, \mathrm{n}=72)$, or $>65$ years $(10.75 \pm 1.09 \mathrm{~m} / \mathrm{s}, \mathrm{n}=46)$ significantly exceeded those in age-matched control subjects $(6.27 \pm 0.44 \mathrm{~m} / \mathrm{s}, \mathrm{n}=16 ; 7.30 \pm 0.54 \mathrm{~mm}, \mathrm{n}=34$; $7.88 \pm 0.59 \mathrm{~m} / \mathrm{s}, \mathrm{n}=36 ; 8.96 \pm 1.16 \mathrm{~m} / \mathrm{s}, \mathrm{n}=18$, respectively) (Figure 2). The arterial stiffness was significantly higher in the hypertensive subjects than in the control subjects $(P<0.001)$. There is no gender difference in the presence of arterial stiffness.

\section{Relationship between the carotid IMT and arterial stiffness}

A significant positive correlation between the carotid IMT and arterial stiffness was found in the control subjects $(r=$ $0.337, P<0.001$ ). We also observed a significant positive correlation between the carotid IMT and arterial stiffness in the hypertensive subjects $(r=0.421, P<0.001)$ (Figure $3)$. Moreover, the slope of the regression line between the carotid IMT to the arterial stiffness was significantly steeper in the hypertensive patients than in the control subjects $(P<0.05)$.

\section{Risk factors for increased arterial stiffness}

Multiple regression analysis showed that homocysteine was independently related to arterial stiffness parameter 


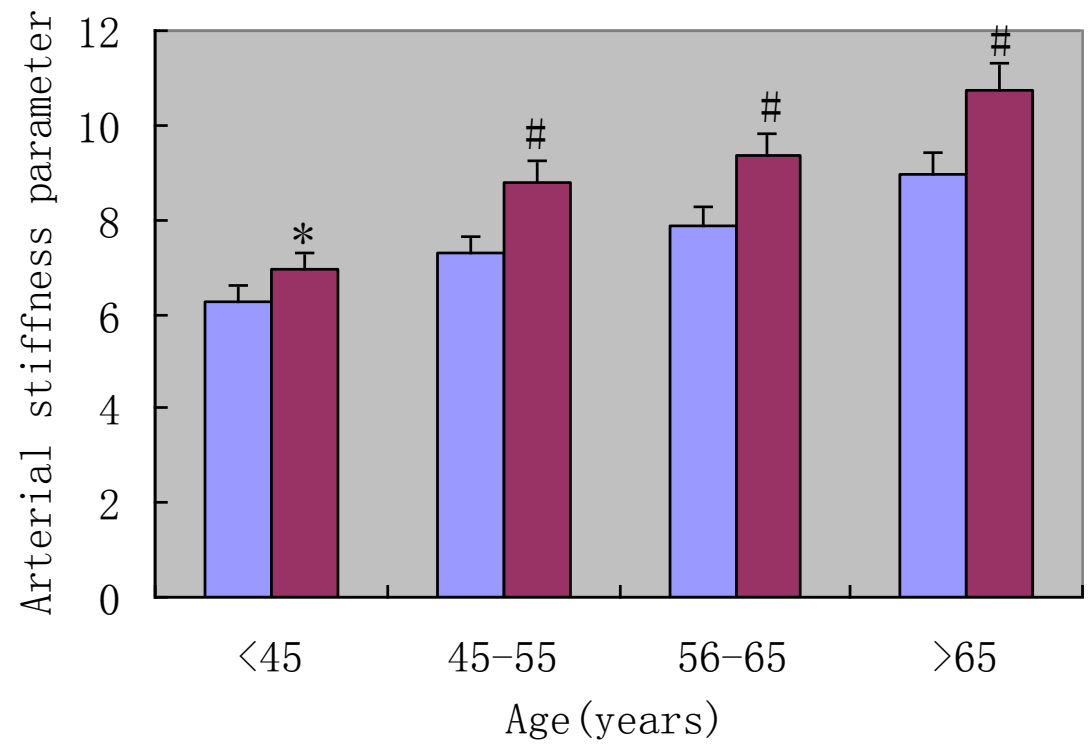

Figure 2. Bar graphs showing mean values of the arterial stiffness parameter in control subjects ( $n=104$ blue bar) and patients with hypertension ( $n=232$ purple bar) by age group. ${ }^{*} \mathrm{P}<0.05, \# \mathrm{P}<0.001$ vs. control subjects
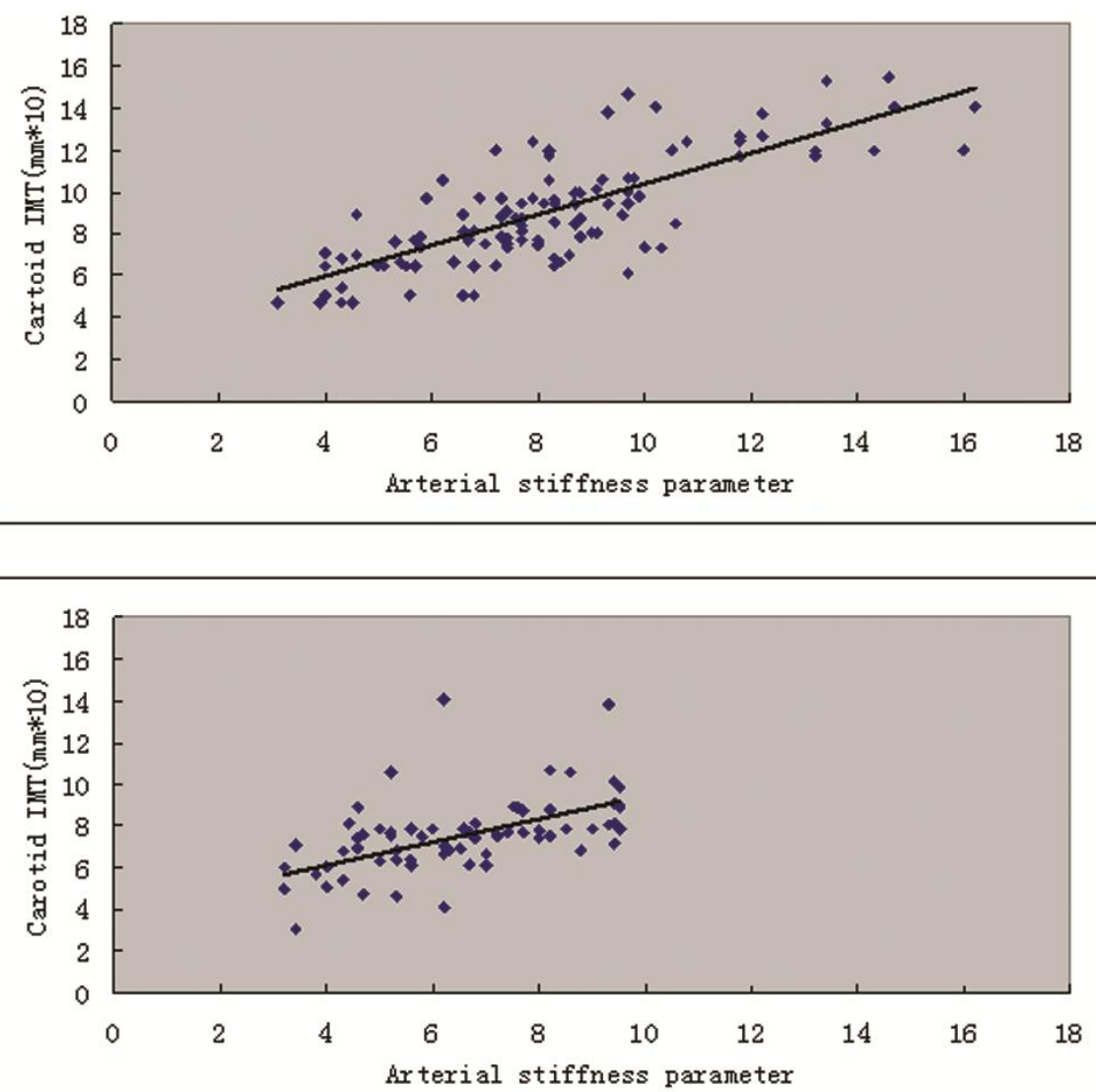

Figure 3. The relationship between the IMT of the carotid artery and arterial stiffness in patients with hypertension $(n=232 ; r=0.421, P<0.001$, see the above figure) and control subjects $(n=104 ; r=0.337, P<0.001$, see the below figure). 

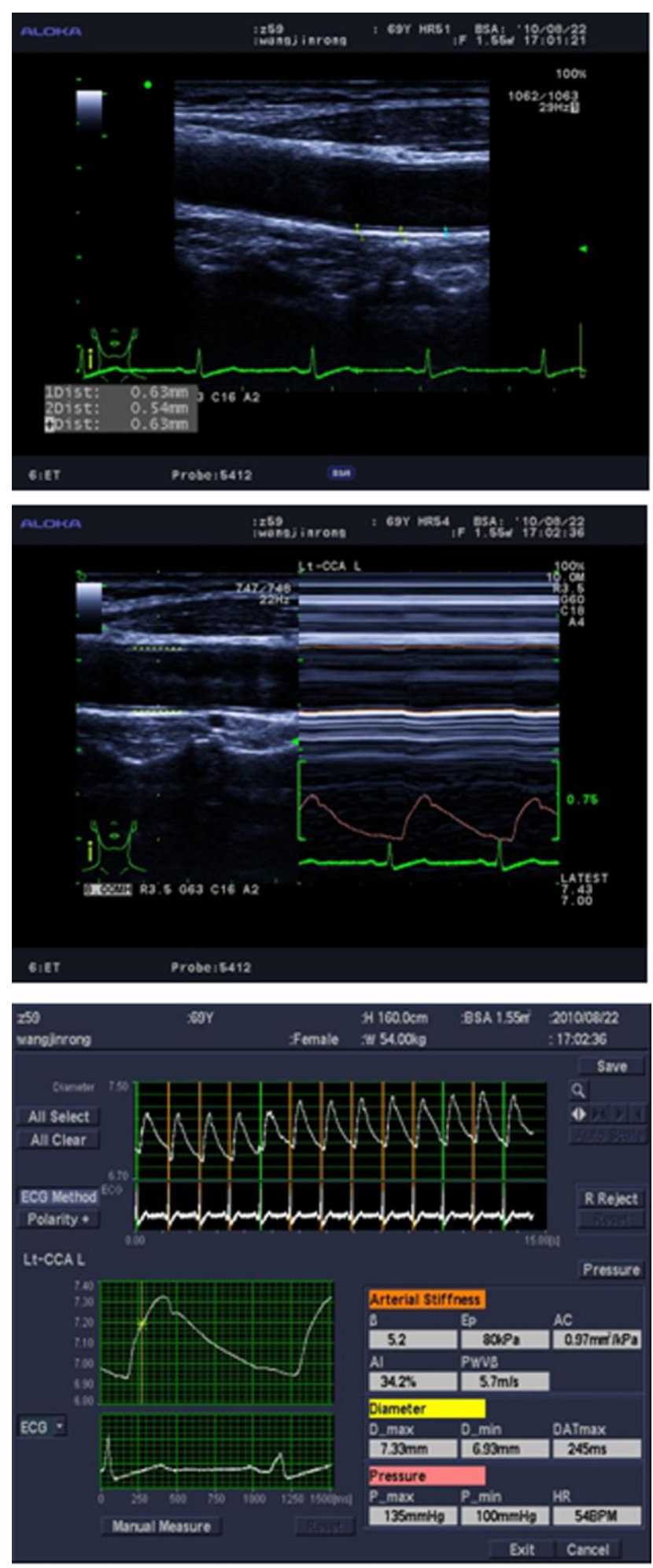

Figure 4. The collecting image of arterial stiffness measured by echo-tracking technology on carotid ultrasonography.

(standardized regression parameter $0.155, \quad \mathrm{P}<0.01$ ) besides that age, smoking, hypertension, eGFR and the roles of HDL-cholesterol were accounted for (Table 2).

\section{Risk factors for increased carotid IMT}

Multiple regression analysis showed not only homocysteine but hs-CRP were independently related to IMT (standardized regression parameters 0.102, $\mathrm{P}<0.01$; $0.117 \mathrm{P}<0.01$; respectively) besides that age, smoking, hypertension and the roles of LDL-cholesterol were accounted for (Table 3).

\section{Multivariate predictors of log-transfurmed homocysteine levels}

The associations of these vitamins including folate, Vit. B6 and Vit. B12, intakes with homocysteine concentrations were examined using multiple linear regression analysis after adjusting for age, gender, cigarette-years, body mass index, hypertension, systolic blood pressure, diastolic blood pressure, total cholesterol, triglyceride, HDL cholesterol levels, LDL cholesterol and fasting blood glucose. Homocysteine were independently related with age, gender, smoking, hypertension, intakes of folate and eGFR (Table 4).

\section{DISCUSSION}

We demonstrated that carotid IMT and arterial stiffness were significantly higher in subjects with hypertension than in age-matched control subjects and found significant correlations between structural and functional changes (as indicated by IMT and arterial stiffness parameter, respectively) in hypertensive patients and control subjects in the present study. It is notable that carotid IMT presented no difference between hypertensive and control groups younger than 45 years of age. On the contrary, arterial stiffness parameter showed obvious increase in the hypertensive group younger than 45 years of age. This finding is consisted with the fact that vascular functional (sclerotic) changes occur prior to structural (atherotic) changes (Alan et al., 2003; Davignon and Ganz, 2004; Yambe et al., 2004).

An association between arterial atherotic (structural) and sclerotic (functional) changes is present not only in hypertensive patients but also in senior healthy subjects aged over 45 years. A comprehensive histopathologic study of medium-to-large caliber blood vessels showed vascular fibrosis was a complex process (Selvin et al., 2010). Aging, hypertension, diabetes, poor renal function and dyslipidemia were significantly associated with increased systemic vascular fibrosis and fatty degeneration (atherosis) (Aronson, 2003; Greenwald, 2007). Such 
Table 2. Risk factors affecting arterial stiffness.

\begin{tabular}{lcc}
\hline Independent variable & Standard regression coefficient & P-value \\
\hline Hypertension & 0.316 & $<0.001$ \\
Systolic blood pressure & 0.221 & $<0.001$ \\
Age & 0.169 & $<0.001$ \\
cigarette-years & 0.142 & 0.0076 \\
HDL-cholesterol & -0.113 & 0.0175 \\
Homocysteine & 0.155 & 0.0035 \\
\hline
\end{tabular}

$R 2=0.330(P<0.001)$. Variables assessed in all subjects included age, gender, $\mathrm{BMI}$, cigarette-years, hypertension, blood pressure, fasting plasma glucose, total cholesterol, triglyceride, HDL cholesterol levels, LDL cholesterol, eGFR, homocysteine,hs-CRP, intake of folate, Vitamin $\mathrm{B}_{6}$ and Vitamin $\mathrm{B}_{12}$. eGFR, estimated glomerular filtration rate; hs-CRP, high-sensitivity $\mathrm{C}$-reactive protein. $R^{2}$, multiple coefficient of determination.

Table 3. Risk factors affecting carotid IMT.

\begin{tabular}{lcc}
\hline Independent variable & Standard regression coefficient & P-value \\
\hline Hypertension & 0.320 & $<0.001$ \\
Systolic blood pressure & 0.262 & $<0.001$ \\
Age & 0.191 & $<0.001$ \\
cigarette-years & 0.174 & 0.0019 \\
LDL-cholesterol & 0.227 & $<0.001$ \\
Hs-CRP & 0.117 & 0.0067 \\
Homocysteine & 0.102 & 0.0078 \\
\hline
\end{tabular}

$\mathrm{R}^{2}=0.361 \quad(\mathrm{P}<0.001)$. Variables assessed in all subjects included age, gender, $\mathrm{BMI}$, cigarette-years, hypertension, blood pressure, fasting plasma glucose, tota cholesterol, triglyceride, HDL cholesterol levels, LDL cholesterol, eGFR, homocysteine,hs-CRP, intake of folate, Vitamin $B_{6}$ and Vitamin $B_{12}$. eGFR, estimated glomerular filtration rate; hs-CRP, high-sensitivity C-reactive protein. $R^{2}$, multiple coefficient of determination.

Table 4. Multivariate predictors of log-transfurmed homocysteine levels.

\begin{tabular}{lcc}
\hline Independent variable & Standard regression coefficient & P-value \\
\hline Age & 0.218 & $<0.001$ \\
Gender $($ male $=0$,femal $=1)$ & -0.147 & $<0.001$ \\
Hypertension & 0.175 & $<0.001$ \\
Cigarette-years & 0.126 & 0.0065 \\
Folate $(\mu \mathrm{m} / \mathrm{d})$ & 0.117 & 0.0142 \\
eGFR $\left(\mathrm{m} / \mathrm{mi} \mathrm{n} / 1.73 \mathrm{~m}^{2}\right)$ & -0.112 & 0.0365 \\
\hline
\end{tabular}

$\mathrm{R}^{2}=0.318 \quad(P<0.001)$, Homocysteine levels were natural logarithm transformed. Abbreviations are listed in Table 1. Variables assessed in all subjects included age, gender, BMI, cigarette-years, body mass index, hypertension, systolic and diastolic blood pressure, fasting plasma glucose, total cholesterol, triglyceride, HDL cholesterol levels, LDL cholesterol.

atherotic and sclerotic changes may be commonly associated with homocysteine, which should be considered to be a potential target for intervention of arterial stiffening and IMT thickening.

Because high plasma homocysteine was considered as a biomarker for metabolic disorders, a positive association of homocysteine with arterial stiffness parameter may support the association between metabolic disorder and increased arterial stiffness (Di Minno et al., 2010). Earlier data suggest that homocysteine levels are associated 
with aortic stiffness in patients with type II diabetes mellitus (Anan et al., 2007) and arterial hypertension (Vyssoulis et al., 2010). In another study (de Bree et al., 2006), such an association between homocysteine levels and arterial stiffness indices was not indicated, pointing to a clear controversy at present. Our study showed the independent relationship between circulating homocysteine levels and arterial stiffness on carotid artery. The possible mechanisms of the relationship between homocysteine and arterial stiffness are not yet fully well established (Cohen et al., 2001; Spoelstra-De Man et al., 2005). However, it is known that elevated homocysteine levels induce oxidative injury to vascular endothelial cells and impair the production of nitric oxide, a strong relaxing factor by the endothelium (Tawakol et al., 1997; van den Bosch et al., 2003; Anan et al., 2007; Cohen et al., 2001; de Bree et al., 2006; Di Minno et al., 2010; Spoelstra-De Man et al., 2005; Vyssoulis et al., 2010).

A significant positive association between hs-CRP and pulse wave velocity has been shown in healthy Japanese men, but the association may become insignificant after adjusting for conventional cardiovascular risk factor (Tomiyama et al., 2004). In the present study, only homocysteine, but not hs-CRP, was associated with arterial stiffness parameter independently of age, gender, BMI, blood pressure and metabolic components. High arterial stiffness was mainly determined by high homocysteine, and not high hs-CRP.

The complex metabolic factors, especially homocysteine, had an important role in this complex development of IMT and arterial stiffness, but the exact mechanism may be a hopeful illuminating factor for intervention in future. There were many complex influence factors of homocysteine, for example dietary factors (Scuteri et al., 2004). Especially, folate intake, but not other B vitamins, significantly negative correlated with homocysteine level. Folate was the needed substrate of the homocysteine metabolism, while vitB6 and vitB12 were only as coenzymes in the process (Nygard et al., 1995). In China, especially in the north, folate levels in the elderly people were below those in the European and American countries. So, it should be strengthen in the elder of nutrition knowledge to pay attention to adequate $B$ vitamins foods and supplements. There was a correlation between cigarette smoking and increased homocysteine level. Some research showed the increased formation of reactive oxygen species in smokers led to sulfydryl oxidation and reduction. Additionally, smoking could inhibit the vigor of methionine synthase and decreased homocysteine concentrations. Smoking could also affect the absorption of B vitamins (Kim et al., 2002). Lastly, even if the intake of folate was a predictor for the homocysteine, the intake of folate is not independent for the development of IMT and arterial stiffness, which was not like the role of homocysteine level. The complex influence factors and the potential mechanism would be explored in the future studies. In conclusion, the study confirmed the association between arterial atherotic (structural) and sclerotic (functional) changes. Homocysteine, but not hs-CRP, associated with the changes of carotid artery IMT and arterial stiffness.

\section{Clinical implications}

The independent association of the level of serum homocysteine with increased arterial stiffness and IMT supports the biologic and mechanistic links between these two entities. Because arterial stiffness may be modifiable, it can be considered a potential target for intervention of IMT. Complex metabolic factors, especially homocysteine, have important roles in this process. However, the deep and exact mechanisms of the roles, including folate, may be focused on in our future investigations.

\section{Potential limitations}

Because of the cross-sectional design, the present study could not explore the causal associations among arterial stiffness, LV diastolic function, hs-CRP and homocysteine. Additional studies with designs to address the relevant questions will be conducted in future.

\section{ACKNOWLEDGMENT}

The authors thank the medical staff and the participants of the study for their valuable contributions. We are thankful to the Aloka Corp., Japan who generously donated the $\alpha-10$ apparatus to our hospital. We also thank Dr. Jie Mao for her writing and editing assistance. This study was funded by the National Natural Science Foundation of China (NO.30872713) and National Key Basic Research and Development Program of China (973 Program, NO.2012CB517503).

\section{DISCLOSURE OF INTEREST}

The authors declare that they have no conflicts of interest concerning this article.

\section{REFERENCES}

Alan S, Ulgen MS, Ozturk O, Alan B, Ozdemir L, Toprak N (2003). Relation between coronary artery disease, risk factors and intimamedia thickness of carotid artery, arterial distensibility and stiffness index. Angiol. 54:261-267.

Anan F, Masaki T, Umeno Y, Yonemochi H, Eshima N, Saikawa T, Yoshimatsu $\mathrm{H}$ (2007). Correlations between homocysteine levels and atherosclerosis in Japanese type 2 diabetic patients. Metab. 10:1390- 
1395.

Aronson D (2003). Cross-linking of glycated collagen in the pathogenesis of arterial and myocardial stiffening of aging and diabetes. J. Hypertens. 21:3-12.

Bahrami H, Bluemke DA, Kronmal R, Bertoni AG, Lloyd-Jones DM, Shahar E, Szklo M, Lima JA (2008). Novel metabolic risk factors for incident heart failure and their relationship with obesity: the MESA (Multi-Ethnic Study of Atherosclerosis) study. J. Am. Coll. Cardiol. 51:1775-1783.

Braunwald E (2008). Biomarkers in heart failure. N. Engl. J. Med. 358:2148-2159.

Chrysohoou C, Pitsavos C, Barbetseas J, Kotroyiannis I, Brili S, Vasiliadou K, Papadimitriou L, Stefanadis C (2009). Chronic systemic inflammation accompanies impaired ventricular diastolic function, detected by Doppler imaging, in patients with newly diagnosed systolic heart failure (Hellenic Heart Failure Study). Heart Vessels 24:22-26.

Cohen JA, Jeffers BW, Stabler S, Schrier RW, Estascio R (2001). Increasing homocysteine levels and diabetic autonomic neuropathy. Auton. Neurosci. 87:268-273.

Davignon J, Ganz P (2004). Role of endothelial dysfunction in atherosclerosis. Circ. 109:27-32.

de Bree A, Mennen LI, Zureik M, Ducros V, Guilland JC (2006). Homocyctseine is not associated with arterial thickness and stiffness in healthy middle-aged French volunteers. Int. J. Cardiol. 113:332340.

Di Minno MN, Tremoli E, Coppola A, Lupoli R, Di Minno G (2010). Homocysteine and arterial thrombosis: Challenge and opportunity. Thromb. Haemost. 103:942-961.

Eren M, Gorgulu S, Uslu N, Celik S, Dagdeviren B, Tezel T (2004). Relation between aortic stiffness and left ventricular diastolic function in patients with hypertension, diabetes, or both. Heart 90:37-43.

Farrar DJ, Greed HD, Wagner WD, Bond MG (1980). Reduction in pulse wave velocity and improvement of aortic distensibility accompanying regression of atherosclerosis in the Rhesus monkey. Circ. Res. 47:425-435.

Greenwald SE (2007). Ageing of the conduit arteries. J. Pathol. 211:157-172.

Ikonomidis I, Tzortzis S, Papaioannou T, Protogerou A, Stamatelopoulos K, Papamichael C, Zakopoulos N, Lekakis J (2008). Incremental value of arterial wave reflections in the determination of left ventricular diastolic dysfunction in untreated patients with essential hypertension. J. Hum. Hypertens. 22:687-698.

Jourdan C, Wühl E, Litwin M, Fahr K, Trelewicz J, Jobs K, Schenk JP, Grenda R, Mehls O, Tröger J, Schaefer F (2005). Normative values for intima-media thickness and distensibility of large arteries in healthy adolescents. J. Hypertens. 23:1707-1715.

Kim JM, Lee H, Chang N (2002). Hyperhomocysteinemia due to shortterm folate deprivation is related to electron microscopic changes in the rat brain. J. Nutr. 132:3418-3421.

Niki K, Sugawara M, Chang D, Harada A, Okada T, Sakai R, Uchida K, Tanaka R, Mumford CE (2002). A new noninvasive measurement system for wave intensity: evaluation of carotid arterial wave intensity and repreducibility. Heart Vessels 17:12-21.

Nygard O, Vollset SE, Refsum H, Stensvold I, Tverdal A, Nordrehaug JE, Ueland M, Kvåle G (1995). Total plasma homocysteine and cardiovascular risk profile. JAMA. 274:1526-1533.

Robinson K (2002). Homocysteine and vascular disease. Eur. Heart J. 19:1482-1484.
Scuteri A, Najjar SS, Muller DC, Andres R, Hougaku H, Metter EJ, Lakatta EG (2004). Metabolic syndrome amplifies the age-associated increases in vascular thickness and stiffness. J. Am. Coll. Cardiol. 43:1388-1395.

Selvin E, Najjar SS, Cornish TC, Halushka MK (2010). A comprehensive histopathological evaluation of vascular medial fibrosis:insights into the pathophysiology of arterial stiffening. Atherosclerosis 208:69-74.

Sharrett AR, Ding J, Criqui MH, Saad MF, Liu K, Polak JF, Folsom AR, Tsai MY, Burke GL, Szklo M (2006). Smoking, diabetes, and blood cholesterol differ in their associations with subclinical atherosclerosis: the Multiethnic Study of Atherosclerosis (MESA). Atheroscler. 186:441-447.

Spoelstra-De Man AM, Smulders YM, Dekker JM, Heine RJ, Bouter LM, Nijpels G, Stehouwer CD (2005). Homocysteine levels are not associated with cardiovascular autonomic function in elderly Caucasian subjects without and with type 2 diabetes mellitus: the Hoom study. J. Int. Med. 258:536-543.

Taniwaki H, Kawagishi T, Emoto M, Shoji T, Kanda H, Maekawa K, Nishizawa Y, Morii H (1999). Correlation between the intima-media thickness of the carotid artery and aortic pulse-wave velocity in patients with type 2 diabetes. Vessel wall properties in type 2 diabetes. Diabetes Care 22:1851-1857.

Tawakol A, Omland T, Gerhard M, Wu JT, Greager MA (1997). Hyperhomocysteinemia is associated with impaired endothelium dependant vasodilatation in humans. Circulation 95:1119-1121.

Tomiyama H, Arai T, Koji Y, Yambe M, Hirayama Y, Yamamoto Y, Yamashina A (2004). The relationship between high-sensitive Creactive protein and pulse wave velocity in healthy Japaneses men. Atheroscler. 174:373-377.

van den Bosch MA, Bloemenkamp DG, Mali WP, Kemmeren JM, Tanis BC, Algra A, Rosendaal FR, van der Graaf Y (2003). Hyperhomocystenemia and risk for peripheral arterial occlusive disease in young women. J. Vasc. Surg. 38:772-778.

Vasan RS, Beiser A, D'Agostino RB, Levy D, Selhub J, Jacques PF, Rosenberg IH, Wilson PW (2003). Plasma homocysteine and risk for congestive heart failure in adults without prior myocardial infarction. JAMA 289:1251-1257.

Vollset SE, Refsum H, Tverdal A, Nygard O, Nordrehaug JE (2001). Plasma total homocysteine and cardiovascular and noncardiovascular mortality:the Hordaland Homocytseine Study. Am. J. Clin. Nutr. 74:130-136.

Vyssoulis G, Karpanou E, Kyvelou SM, Adamopoulos D, Gialernios T, Gymnopoulou E, Cokkinos D, Stefanadis C (2010). Associations between plasma homocysteine levels, aortic stiffness and wave reflection in patients with arterial hypertension, isolated office hypertension and normotensive controls. J. Hum. Hypertens. 24:183-189.

Welch GN, Loscalzo J (1998). Homocysteine and atherotrombosis. N. Eng. J. Med. 338:1042-1050.

Yambe M, Tomiyama H, Hirayama Y, Gulniza Z, Takata Y, Koji Y, Motobe K, Yamashina A (2004). Arterial stiffening as a possible risk factor for both atherosclerosis and diastolic heart failure. Hypertens. Res. 27:625-631.

Yoshino K, Nishide M, Sankai T, Inagawa M, Yokota K, Moriyama Y, Ikeda A, Noda H, Yamagishi K, Tanigawa T, Iso H (2010). Validity of brief food frequency questionnaire for estimation of dietary intakes of folate, vitamins $\mathrm{B} 6$ and $\mathrm{B} 12$, and their associations with plasma homocysteine concentrations. Int. J. Food Sci. Nutr. 61:61-67. 